\title{
Significant Clinical Indexes of Exercise-Induced Pulmonary Hypertension in Patients With Connective Tissue Disease
}

\author{
Satoko Ojima, MD; Takuro Kubozono, MD; Keishi Saihara, MD; Takahiro Miyauchi, MD; \\ Shin Kawasoe, MD; Kayoko Kubota, MD; Sanae Shigemizu, MD; \\ Hideo Ohtsubo, MD; Masaaki Miyata, MD; Mitsuru Ohishi, MD
}

\begin{abstract}
Background: Pulmonary hypertension (PH) is an important cause of morbidity in patients with connective tissue disease (CTD), and an early stage of $\mathrm{PH}$ could present as exercise-induced $\mathrm{PH}(\mathrm{EIPH})$. This study investigated the significant clinical indexes of EIPH in patients with CTD.
\end{abstract}

\begin{abstract}
Methods and Results: We enrolled 63 patients with CTD who did not have PH at rest. All patients underwent the 6-min walk test (6MWT), and systolic pulmonary artery pressure (SPAP) was evaluated on echocardiography before and after 6MWT. EIPH was defined as SPAP $\geq 40 \mathrm{mmHg}$ after 6 WMT. Thirty-five patients had EIPH. On univariate logistic analysis, SPAP at rest, log brain natriuretic peptide (BNP), vital capacity (VC), and forced expiratory volume in $1 \mathrm{~s}$ (FEV1.0) were significantly correlated with EIPH. On multiple logistic analysis, SPAP at rest and VC were independent predictors of EIPH, whereas FEV1.0 and log BNP were not significantly associated with EIPH. The area under the receiver operating characteristics curve between EIPH and BNP, SPAP at rest, VC or FEV1.0 was $0.67,0.76,0.74$, and 0.75 , respectively.
\end{abstract}

Conclusions: SPAP at rest and respiratory function, especially VC, could be independent predictors of EIPH in patients with CTD.

Key Words: Connective tissue disease; Exercise-induced pulmonary hypertension; Predictor; Respiratory function; Vital capacity

$\mathbf{P}$ ulmonary hypertension $(\mathrm{PH})$ is defined as high blood pressure in the pulmonary arteries and is an important cause of morbidity and mortality in connective tissue disease (CTD). ${ }^{1}$ In the REVEAL registry, the CTD patients with $\mathrm{PH}$ had a lower survival rate and freedom from hospitalization rate at 1 year compared with idiopathic PH patients. ${ }^{2}$ In recent years, however, survival rates in patients with CTD and PH have improved because of the early detection of $\mathrm{PH}$ and evidence-based treatment. 3,4 Thus, early detection of $\mathrm{PH}$ and subsequent intervention in patients with CTD is imperative.

PH is a hemodynamic and pathophysiological state involving an elevation in mean pulmonary artery pressure (PAP) $\geq 25 \mathrm{mmHg}$ at rest on right heart catheterization (RHC) ${ }^{5,6}$ Despite RHC being a gold standard to diagnose $\mathrm{PH}$, it is an invasive examination and is difficult to perform in all patients with CTD. Thus, echocardiography at rest is the leading modality for screening $\mathrm{PH}$ and is used to estimate the systolic PAP (SPAP) based on tricuspid regurgitation pressure gradient on echocardiography..$^{7-9}$ Furthermore, PH might progress gradually, and echocardiography is non-invasive and appropriate to evaluate changes over time.

Recently, the topic of exercise-induced PH (EIPH) has garnered attention, due to being a marker for the risk of developing resting $\mathrm{PH} .{ }^{10} \mathrm{EIPH}$ on exercise echocardiography has recently been suggested as a potentially useful tool. ${ }^{11} \mathrm{~A}$ total of $40 \%$ of CTD patients with normal resting SPAP developed abnormally high values at peak exercise, ${ }^{12}$ and mean PAP after exercise (but not mean PAP at rest) correlated with the development time of PH. ${ }^{13} \mathrm{CTD}$ is not only characterized by the presence of cardiopulmonary functional disorder but also various organ failures. Furthermore, lung disease or left cardiac dysfunction is also a complication of CTD, and these functional disorders are related to $\mathrm{PH}$, thereby necessitating the establishment of a multidisciplinary approach to evaluate $\mathrm{PH}$ in patients with CTD. ${ }^{5}$ To date, however, factors associated with EIPH remain undetermined. Thus, this study investigated the factors related to EPIH in patients with CTD.

Received September 9, 2019; revised manuscript received October 10, 2019; accepted October 15, 2019; J-STAGE Advance Publication released online November 9, 2019 Time for primary review: 1 day

Department of Cardiovascular Medicine and Hypertension, Graduate School of Medical and Dental Sciences, Kagoshima University, Kagoshima (S.O., T.K., K.S., T.M., S.K., K.K., M.M., M.O.); Center for Rheumatic Diseases, Japanese Red Cross Kagoshima Hospital, Kagoshima (S.S., H.O.), Japan

M.O. is a member of Circulation Reports' Editorial Team.

Mailing address: Takuro Kubozono, MD, Department of Cardiovascular Medicine and Hypertension, Graduate School of Medical and Dental Sciences, Kagoshima University, 8-35-1 Sakuragaoka, Kagoshima 890-8544, Japan. E-mail: kubozono@m.kufm. kagoshima-u.ac.jp

ISSN-2434-0790 All rights are reserved to the Japanese Circulation Society. For permissions, please e-mail: cr@j-circ.or.jp 


\begin{tabular}{|c|c|c|c|}
\hline & $\begin{array}{l}\text { EIPH } \\
(n=35)\end{array}$ & $\begin{array}{l}\text { Non-EIPH } \\
(n=28)\end{array}$ & P-value \\
\hline Female (\%) & 94 & 89 & 0.6480 \\
\hline Age (years) & $61 \pm 15$ & $55 \pm 12$ & 0.1057 \\
\hline Height (cm) & $153 \pm 9$ & $157 \pm 8$ & 0.0786 \\
\hline Weight (kg) & $52 \pm 12$ & $54 \pm 11$ & 0.5094 \\
\hline BMI $\left(\mathrm{kg} / \mathrm{m}^{2}\right)$ & $22.1 \pm 3.8$ & $22.0 \pm 4.1$ & 0.9350 \\
\hline $\mathrm{BSA}\left(\mathrm{m}^{2}\right)$ & $1.47 \pm 0.20$ & $1.52 \pm 0.16$ & 0.2539 \\
\hline $\mathrm{SBP}$ at rest $(\mathrm{mmHg})$ & $129 \pm 17$ & $117 \pm 13$ & 0.0035 \\
\hline $\mathrm{HR}$ at rest (beats/min) & $72 \pm 11$ & $68 \pm 10$ & 0.1230 \\
\hline $\mathrm{PaO}_{2}$ at rest $(\mathrm{mmHg})$ & $89 \pm 13$ & $89 \pm 11$ & 0.9514 \\
\hline $\mathrm{SpO}_{2}$ at rest (\%) & $98 \pm 1$ & $98 \pm 1$ & 0.8897 \\
\hline $\mathrm{SpO}_{2}$ after $6 \mathrm{MWT}(\%)$ & $94 \pm 6$ & $97 \pm 2$ & 0.0201 \\
\hline 6MWD (m) & $442 \pm 151$ & $478 \pm 96$ & 0.2805 \\
\hline Hypertension (\%) & 60 & 25 & 0.0101 \\
\hline Dyslipidemia (\%) & 54 & 50 & 0.8026 \\
\hline Diabetes mellitus (\%) & 14 & 18 & 0.7400 \\
\hline IP (\%) & 17 & 7 & 0.2825 \\
\hline \multicolumn{4}{|l|}{ Medication } \\
\hline Prednisolone (\%) & 66 & 50 & 0.3032 \\
\hline Ca blocker (\%) & 34 & 29 & 0.7864 \\
\hline ARB/ACEI (\%) & 31 & 7 & 0.0270 \\
\hline Statin (\%) & 17 & 14 & 0.4023 \\
\hline $\mathrm{PGI}_{2}(\%)$ & 14 & 7 & 0.4478 \\
\hline
\end{tabular}

Data given as mean $\pm \mathrm{SD}$ or $\%$. 6MWD, 6-min walking distance; $6 \mathrm{MWT}, 6$-min walk test; $\mathrm{ACEl}$, angiotensin-converting enzyme inhibitor; ARB, angiotensin II receptor blocker; BMI, body mass index; BSA, body surface area; CTD, connective tissue disease; EIPH, exercise-induced pulmonary hypertension; HR, heart rate; IP, interstitial pneumonia; $\mathrm{PaO}_{2}$, partial pressure of arterial oxygen; $\mathrm{PGl}_{2}$, prostaglandin $\mathrm{l}_{2} ; \mathrm{SBP}$, systolic blood pressure; $\mathrm{SpO}_{2}$, oxygen saturation of peripheral artery.

\section{Methods}

In this study, we enrolled 63 consecutive patients with CTD who did not have PH at rest at Japanese Red Cross Kagoshima Hospital (Kagoshima, Japan). All patients were diagnosed with CTD in accordance with the diagnostic criteria of the American College of Rheumatology. ${ }^{14}$ While $\mathrm{PH}$ at rest was defined as estimated right ventricular systolic pressure $\geq 40 \mathrm{mmHg}$ on echocardiography, right ventricular systolic pressure was considered equivalent to SPAP. In the present study cohort, no patient had left ventricular (LV) dysfunction, moderate or severe valvular disease at rest, or atrial fibrillation.

All patients underwent 6-min walk test (6MWT) to assess exercise capacity and also underwent echocardiography before and immediately after 6MWT to detect EIPH. They underwent blood sampling and pulmonary function test before the 6MWT. We measured brain natriuretic peptide (BNP) using a completely automated sample selective analyzer with a commercially available assay (AIA-360; TOSOH Bioscience, San Francisco, CA, USA). Then, we evaluated pulmonary function using FUDAC-77 (Fukuda Denshi, Tokyo, Japan).

This study was approved by the Institutional Ethics Committee of the Graduate School of Medical and Dental Sciences, Kagoshima University and Japanese Red Cross Kagoshima Hospital, and conformed to the guidelines of the Declaration of Helsinki. We obtained written informed consent from all patients for the use and publication of their data.

\section{MWT}

In this study, all patients underwent 6MWT after $15 \mathrm{~min}$ rest based on the American Thoracic Society guidelines for the standardization of 6MWT. ${ }^{15}$ The $6 \mathrm{MWT}$ was performed on a flat 25-m straight-line course. Then, we performed arterial blood gas analysis and evaluated blood pressure (BP), heart rate (HR), and oxyhemoglobin saturation $\left(\mathrm{SpO}_{2}\right)$ measured on pulse oximetry at rest. In addition, we monitored $\mathrm{SpO}_{2}$ and $\mathrm{HR}$ every $1 \mathrm{~min}$. Immediately after $6 \mathrm{MWT}$, all patients lay down again, and $\mathrm{BP}, \mathrm{HR}$, and $\mathrm{SpO}_{2}$ were recorded every $1 \mathrm{~min}$ for the next $6 \mathrm{~min}$. BP and HR were recorded using automatic monitoring ( $\mathrm{H} 55$; Terumo, Tokyo, Japan), and $\mathrm{SpO}_{2}$ was evaluated using the pocket $\mathrm{SpO}_{2}$ monitor WEC-7201 (Nihon Kohden, Tokyo, Japan).

\section{Echocardiography}

We performed transthoracic echocardiography using conventional methods with an ultrasound machine (Vivid E9 pro; GE Healthcare, Horten, Norway), equipped with a $1.5-4.6-\mathrm{MHz}$ transducer at rest and immediately after 6MWT. We then evaluated LV end-diastolic dimension (LVDd), LV end-systolic dimension, interventricular septum thickness (IVSth), and posterior LV wall thickness (PWth) on parasternal long-axis view. LV mass was obtained using the Devereux formula: $0.8 \times\left[1.04\left\{(\text { IVSth }+ \text { LVDd+PWth })^{3-}\right.\right.$ $\left.\left.(\mathrm{LVDd})^{3}\right\}\right]+0.6 .^{16}$ Next, pulse Doppler recording of the mitral flow velocity was obtained on apical 4-chamber view by placing the sample volume between the tips of the mitral leaflets. We then measured the peak early (E) and late diastolic (A) transmitral flow velocities, E/A ratio, and 


\begin{tabular}{|c|c|c|c|}
\hline & $\begin{array}{l}\text { EIPH } \\
(n=35)\end{array}$ & $\begin{array}{c}\text { Non-EIPH } \\
(n=28)\end{array}$ & P-value \\
\hline WBC $(\mu / \mathrm{L})$ & $5,727 \pm 1,921$ & $5,052 \pm 1,553$ & 0.1374 \\
\hline $\mathrm{Hb}(\mathrm{g} / \mathrm{dL})$ & $12.2 \pm 1.6$ & $12.1 \pm 1.5$ & 0.8835 \\
\hline BUN (mg/dL) & $17.4 \pm 7.5$ & $12.9 \pm 3.9$ & 0.0055 \\
\hline $\mathrm{Cr}(\mathrm{mg} / \mathrm{dL})$ & $0.77 \pm 0.25$ & $0.68 \pm 0.14$ & 0.0968 \\
\hline $\mathrm{BNP}(\mathrm{pg} / \mathrm{mL})$ & $47.4 \pm 45.3$ & $25.4 \pm 16.4$ & 0.0174 \\
\hline Log BNP & $1.53 \pm 0.36$ & $1.31 \pm 0.30$ & 0.0118 \\
\hline FBS (mg/dL) & $102 \pm 21$ & $94 \pm 13$ & 0.1222 \\
\hline $\mathrm{HbA1C}(\%)$ & $5.8 \pm 0.5$ & $5.7 \pm 0.5$ & 0.6941 \\
\hline LDL-C (mg/dL) & $115 \pm 33$ & $118 \pm 30$ & 0.7541 \\
\hline CRP (mg/dL) & $0.25 \pm 0.56$ & $0.11 \pm 0.10$ & 0.1969 \\
\hline $\mathrm{ESR}(\mathrm{mm})$ & $27 \pm 29$ & $23 \pm 25$ & 0.5333 \\
\hline
\end{tabular}

Data given as mean \pm SD. BNP, brain natriuretic peptide; BUN, blood urea nitrogen; $\mathrm{Cr}$, creatinine; CRP, C-reactive protein; ESR, erythrocyte sedimentation rate; FBS, fasting blood sugar; Hb, hemoglobin; HbA1C, glycosylated hemoglobin A; LDL-C, low-density lipoprotein cholesterol; WBC, white blood cells. Other abbreviations as in Table 1.

\begin{tabular}{|c|c|c|c|}
\hline & $\begin{array}{l}\text { EIIPH } \\
(n=35)\end{array}$ & $\begin{array}{c}\text { Non-EIPH } \\
(n=28)\end{array}$ & P-value \\
\hline \multicolumn{4}{|l|}{ Echocardiography } \\
\hline LVDd (mm) & $42.6 \pm 5.3$ & $43.3 \pm 5.0$ & 0.5901 \\
\hline LVDs (mm) & $25.4 \pm 3.7$ & $26.3 \pm 4.2$ & 0.4080 \\
\hline LVM (g) & $167.7 \pm 55.3$ & $150.6 \pm 37.6$ & 0.1674 \\
\hline $\mathrm{LAD}(\mathrm{mm})$ & $32.7 \pm 5.1$ & $32.0 \pm 4.4$ & 0.5528 \\
\hline LVEF (\%) & $70.0 \pm 5.5$ & $70.0 \pm 6.1$ & 0.9615 \\
\hline E/A ratio & $0.98 \pm 0.31$ & $1.17 \pm 0.42$ & 0.0396 \\
\hline Deceleration time (ms) & $209 \pm 53$ & $212 \pm 38$ & 0.8239 \\
\hline$E / e^{\prime}$ & $11.7 \pm 5.2$ & $9.4 \pm 3.3$ & 0.1131 \\
\hline Pericardial effusion (\%) & 14 & 21 & 0.5174 \\
\hline SPAP at rest $(\mathrm{mmHg})$ & $32.6 \pm 4.6$ & $27.9 \pm 4.4$ & $<0.0001$ \\
\hline SPAP after 6MWT (mmHg) & $51.9 \pm 7.9$ & $33.1 \pm 4.8$ & $<0.0001$ \\
\hline \multicolumn{4}{|l|}{ Pulmonary function } \\
\hline VC (L) & $2.29 \pm 0.75$ & $2.88 \pm 0.54$ & 0.0008 \\
\hline FEV1.0 (L) & $1.80 \pm 0.59$ & $2.30 \pm 0.51$ & 0.0008 \\
\hline DLCO (\%) & $90.4 \pm 27.0$ & $87.9 \pm 18.0$ & 0.6740 \\
\hline
\end{tabular}

Data given as mean \pm SD or \%. A, peak atrial-systolic transmitral flow velocity; DLCO, diffusing capacity of the lung carbon monoxide; E, peak early diastolic transmitral flow velocity; e', early diastolic mitral annular velocity; FEV1.0, forced expiratory volume in $1 \mathrm{~s}$; LAD, left atrial diameter; LVDd, left ventricular end-diastolic dimension; LVDs, left ventricular end-systolic dimension; LVEF, left ventricular ejection fraction; LVM, left ventricular mass; SPAP, systolic pulmonary artery pressure; VC, vital capacity. Other abbreviations as in Table 1.

deceleration time of the E wave, and we measured e', the early diastolic mitral annular velocity on the septal side. In addition, the tricuspid regurgitation peak velocity (TRV) was evaluated and SPAP was calculated using the modified Bernoulli equation: SPAP $=4 \times \mathrm{TRV}^{2}+$ right atrial $(\mathrm{RA})$ pressure. The RA pressure was evaluated from the inferior vena cava diameter and collapsibility, according to the guidelines of the American Society of Echocardiography. ${ }^{17}$ Furthermore, SPAP was measured to assess EIPH at rest and immediately after 6MWT. We defined EIPH as SPAP at rest $<40 \mathrm{mmHg}$ and SPAP after $6 \mathrm{MWT} \geq 40 \mathrm{mmHg}$.

\section{Statistical Analysis}

All continuous variables are expressed as mean $\pm \mathrm{SD}$, and categorical variables are expressed as percentages. In addition, differences between the 2 groups for continuous and categorical variables were assessed using the Student's unpaired t-test and the chi-squared test, respectively.

We performed the univariate logistic regression analysis to evaluate the correlation between EIPH and clinical variables, including systolic BP (SBP) at rest, HR at rest, SPAP at rest, BNP, vital capacity (VC), forced expiratory volume in $1 \mathrm{~s}$ (FEV1.0) and diffusing capacity of the lung carbon monoxide (DLCO). In addition, the independence of the association between variables was tested on multiple logistic regression analysis, and receiver operating characteristics (ROC) analysis was used to test the ability of the variable to discriminate between the presence and absence of EIPH. Finally, $\mathrm{P}<0.05$ was considered statistically significant. All comparisons in this study were performed using JMP Pro version 14 (SAS Institute, Cary, NC, USA). 


\begin{tabular}{|lccc|}
\hline \multicolumn{4}{|c|}{ Table 4. Univariate Indicators of EIPH in CTD Patients } \\
& OR & $95 \%$ Cl & P-value \\
SBP at rest & 1.05 & $1.01-1.10$ & 0.0028 \\
HR at rest & 1.04 & $0.99-1.09$ & 0.1157 \\
SPAP at rest & 1.27 & $1.10-1.46$ & $<0.0001$ \\
Log BNP & 7.90 & $1.44-43.4$ & 0.0100 \\
VC & 0.24 & $0.09-0.61$ & 0.0006 \\
FEV1.0 & 0.19 & $0.07-0.56$ & 0.0006 \\
DLCO & 1.00 & $0.98-1.03$ & 0.6685 \\
\hline
\end{tabular}

Abbreviations as in Tables 1-3.

\begin{tabular}{|c|c|c|c|}
\hline \multicolumn{4}{|l|}{ Model 1} \\
\hline SPAP at rest & 1.23 & $1.05-1.44$ & 0.0109 \\
\hline VC & 0.33 & $0.12-0.92$ & 0.0348 \\
\hline Log BNP & 2.93 & $0.39-22.15$ & 0.2977 \\
\hline \multicolumn{4}{|l|}{ Model 2} \\
\hline SPAP at rest & 1.22 & $1.05-1.42$ & 0.0085 \\
\hline FEV1.0 & 0.30 & $0.09-1.02$ & 0.0537 \\
\hline Log BNP & 2.35 & $0.32-17.49$ & 0.4036 \\
\hline
\end{tabular}

Model 1, adjusted for SPAP at rest, VC, log BNP; model 2, adjusted for SPAP at rest, FEV1.0, log BNP. Abbreviations as in Tables 1-3.

\section{Results}

Table 1 lists the baseline patient characteristics. In this study, EIPH was diagnosed in 35 patients (EIPH group), and 28 were non-EIPH patients (non-EIPH group). No significant difference was observed in gender or mean age between the 2 groups. In the EIPH group, SBP at rest was significantly higher than in the non-EIPH group (SBP, $129 \pm 17 \mathrm{mmHg}$ vs. $117 \pm 13 \mathrm{mmHg}, \mathrm{P}=0.0035$ ). Although $\mathrm{SpO}_{2}$ at rest was not significantly different between the 2 groups, $\mathrm{SpO}_{2}$ after $6 \mathrm{MWT}$ in the EIPH group was significantly lower than in the non-EIPH group. We observed no significant differences in 6-min walk distance between the 2 groups (EIPH group vs. non-EIPH group, $442 \pm 151 \mathrm{~m}$ vs. $478 \pm 96 \mathrm{~m}, \mathrm{P}=0.2805)$. In the EIPH group, log $\mathrm{BNP}$ was significantly higher than in the non-EIPH group (Table 2; $\mathrm{P}=0.0118$ ). In addition, $\mathrm{C}$-reactive protein and erythrocyte sedimentation rate were not significantly different between the 2 groups.

Table 3 lists the cardiac and pulmonary function according to EIPH status. In the EIPH group, SPAP at rest and also after 6MWT were significantly higher than in the non-EIPH group (SPAP at rest, $32.6 \pm 4.6 \mathrm{mmHg}$ vs. $27.9 \pm 4.4 \mathrm{mmHg}$, $\mathrm{P}<0.0001$; SPAP after 6MWT, $51.9 \pm 7.9 \mathrm{mmHg}$ vs. $33.1 \pm 4.8 \mathrm{mmHg}, \mathrm{P}<0.0001)$. We observed no significant differences in LV diameter, LV mass, left atrial diameter, ejection fraction or E/e' between the 2 groups. In addition, VC and FEV1.0 in the EIPH group were significantly lower compared with the non-EIPH group (VC, $2.29 \pm 0.75 \mathrm{~L}$ vs. $2.88 \pm 0.54 \mathrm{~L}, \mathrm{P}=0.0008$; FEV1.0, $1.80 \pm 0.59 \mathrm{~L}$ vs. $2.30 \pm 0.51 \mathrm{~L}$, $\mathrm{P}=0.0008$ ), whereas DLCO was not significantly different between the 2 groups.

\section{EIPH and Clinical Variables}

Table 4 lists the univariate logistic regression analysis between EIPH and clinical variables. SBP at rest, SPAP at rest, $\log$ BNP, VC, and FEV1.0 were significantly correlated with EIPH, but DLCO was not.

Multiple logistic regression analysis of EIPH is given in Table 5. In model 1, SPAP at rest and VC were independent predictors of EIPH, whereas log BNP was not significant. In model 2, SPAP at rest was an independent predictor of EIPH. Although FEV1.0 and log BNP were not significantly associated with EIPH, FEV1.0 had a tendency towards being a predictor of EIPH.

\section{ROC Curve Analysis}

We performed ROC curve analysis on the ability of BNP, SPAP at rest, VC and FEV1.0 to predict EIPH (Figure).
The area under the ROC curve (AUC) for BNP (Figure A) was 0.67 , with the highest discriminating sensitivity and specificity at 0.40 and 0.93 , respectively, at $\mathrm{BNP}=49.3 \mathrm{pg} / \mathrm{mL}$. In addition, the AUC for SPAP at rest (Figure B), VC (Figure C), and FEV1.0 (Figure D) were 0.76, 0.74, and 0.75 , respectively. The highest discriminating sensitivity and specificity were 0.66 and 0.79 , respectively, at SPAP at rest $=31.1 \mathrm{mmHg}, 0.69$ and 0.79 , respectively, at $\mathrm{VC}=2.53 \mathrm{~L}$, and 0.77 and 0.68 , respectively, at FEV1.0 $=2.14 \mathrm{~L}$. Overall, the AUC and sensitivity of SPAP at rest, VC, and FEV1.0 were higher than those for BNP.

\section{Discussion}

This study investigated the correlation between EIPH and various clinical parameters inducing cardiac and pulmonary functions in patients with CTD, and identified the predictors of EIPH. SPAP at rest and the parameter of respiratory function, VC, were significant predictors of EIPH, although BNP and FEV1.0 were not. Furthermore, the cut-offs of BNP, SPAP at rest, VC, and FEV1.0 to predict EIPH were also calculated. Thus, SPAP at rest, VC, and FEV1.0 might be better predictors for EIPH than BNP.

$\mathrm{PH}$ is a predictor of outcome in CTD that warrants early intervention. Given that EIPH is considered a preliminary stage of PH, screening of EIPH is crucial. EIPH has also been reported to be a predictor of future $\mathrm{PH}$ in patients with systemic sclerosis (SSc). ${ }^{18}$ Although $\mathrm{PH}$ is diagnosed on $\mathrm{RHC}$ in clinical practice, we performed a simple screening test for EIPH on stress echocardiography in 63 patients with CTD, and diagnosed 38 patients $(56 \%)$ with EIPH. The EIPH screening test should be simple, non-invasive, with no need for specialized and expensive equipment. Moreover, EIPH screening should be available not only at large hospitals but also at various facilities, including clinics. We believe that the present results could be critical and useful in the screening of EIPH in patients with CTD because the methods are simple, and non-invasive, and require no specialized equipment.

Several studies have established a correlation between EIPH and other factors. DLCO was found to correlate significantly with exercise SPAP, and lower DLCO was found to be associated with a higher risk of developing higher SPAP. ${ }^{19}$ In the present study, however, VC, but not DLCO, was a significant predictor of EIPH. We speculate that DLCO had not decreased in the present patients at the time of the study because all of the patients were in the early stage of PH. To the best of our knowledge, this is the first study to demonstrate a significant correlation between 

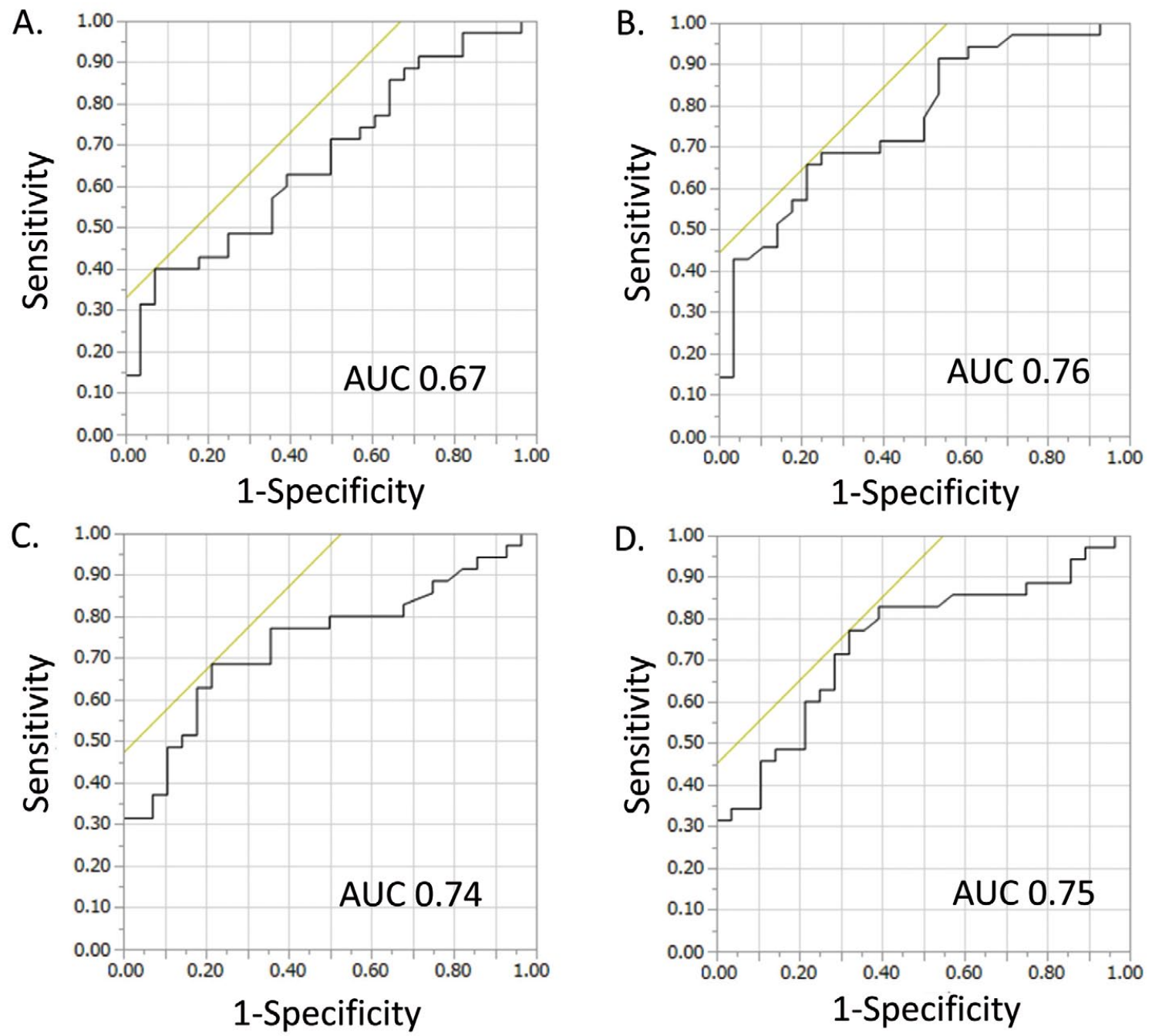

Figure. Receiver operating characteristic curve analysis to predict exercise-induced pulmonary hypertension (EIPH) using $(\mathbf{A})$ brain natriuretic peptide (sensitivity, 0.40; specificity, 0.93; cut-off, $49.3 \mathrm{pg} / \mathrm{mL}$ ); (B) systolic pulmonary artery pressure at rest (sensitivity, 0.66; specificity, 0.79; cut-off, $31.1 \mathrm{mmHg}$ ); (C) vital capacity (sensitivity, 0.69; specificity, 0.79; cut-off, 2.53L); and (D) forced expiratory volume in 1s (sensitivity, 0.77; specificity, 0.68; cut-off, 2.14L) in patients with connective tissue disease. AUC, area under the curve.

EIPH and VC. Given that the respiratory function parameter VC can be evaluated using a simple and non-invasive method, it is useful for detecting EIPH. There are several reports on the impairment of respiratory function in CTD patients. CTD patients often have respiratory diseases, such as airway disease, parenchymal lung disease and pleurisy. Airway disease causes a decrease in $\%$ FEV1.0, while parenchymal lung disease and pleurisy cause a decrease in VC. Also, prevalence of bronchitis in patients with RA was higher than that in patients without RA. ${ }^{20} \mathrm{VC}$ and FEV1.0 in RA patients was significantly lower than in the control group. 21,22 Pulmonary function is associated with SPAP at rest in the general population ${ }^{\mathbf{2 3 , 2 4}}$ and there may be a significant relationship between pulmonary function and SPAP in CTD patients. In contrast, the prevalence of interstitial pneumonia (IP) with RA is $0.86-6.9 \%{ }^{25}$ IP is considered an important factor for prognosis, and IP is caused by sustained RA activity. Although DLCO was reported to be significantly related to EIPH in CTD patients, ${ }^{26}$ this significant relationship between DLCO and EIPH was not seen in the present study. The present patients were at an early stage of CTD, and hence DLCO had not declined because IP had not developed, but VC and FEV1.0 may have declined due to bronchitis and pleurisy even in the early stage. It is not clear, however, why VC and EIPH were related, and further study is needed.

In addition, a correlation between EIPH and LV function has been reported in CTD. EIPH was found to be associated with both increased exercise LV filling pressure and exercise pulmonary vascular resistance (PVR) in patients with SSc. ${ }^{11}$ Peak exercise SPAP has also been found to be affected by age, interstitial lung disease, and right ventricular and LV diastolic dysfunction and, in only $5 \%$ of patients, it was associated with an increase in PVR during exercise. ${ }^{12}$ The heterogeneity of the EIPH mechanisms in CTD, such as pulmonary vascular dysfunction, respiratory dysfunction, 
and LV dysfunction. In the present study, SBP after exercise in the EIPH group was significantly higher than that in the non-EIPH group, possibly indicating that the LV wall stiffness was exacerbated by the increased SBP that resulted in the development of EIPH.

We determined the cut-offs of BNP, SPAP at rest, VC or FEV1.0 for detecting EIPH on ROC analysis in CTD patients. It is difficult to perform echocardiography or RHC during exercise in order to diagnose EIPH; therefore, if we can screen earlier, using these cut-offs, this study would make a significant contribution to the clinical stratification of CTD patients.

BNP has been reported to be associated with the prognosis and severity of PH. A high level of plasma BNP was found to be independently correlated with increased mortality rates in primary $\mathrm{PH}$, and the baseline BNP cut-off was $150 \mathrm{pg} / \mathrm{mL} .{ }^{27}$ Furthermore, BNP is a useful index for screening PH in patients with SSc, at a cut-off of $64 \mathrm{pg} / \mathrm{mL} .^{28}$ In the present study, the cut-off of BNP for EIPH was $49.3 \mathrm{pg} / \mathrm{mL}$ because the present patients were in the early stage of PH. Hence, we suggest that BNP $>50 \mathrm{pg} / \mathrm{mL}$ be used as the screening value for EIPH in patients with CTD.

\section{Study Limitations}

This study had several limitations. First, the data were collected from a single center, and the sample size was small. Thus, multicenter and large-scale studies are required to confirm the present results. Second, although $\mathrm{RHC}$ is the gold standard according to the definition of $\mathrm{PH}, \mathrm{RHC}$ was not performed in this study. In the facility where the subjects were enrolled, there are specialists for collagen disease or cardiovascular disease, but there is no equipment for cardiac catheterization and hence RHC could not be performed. In addition, it was ethically difficult to perform right heart categorization, which is an invasive technique, because patients had normal SPAP at rest. Therefore, we assessed SPAP indirectly on echocardiography, given its correlation with RHC assessment. Further studies measuring SPAP on echocardiography and RHC at exercise simultaneously are needed to confirm the present results. Third, because we detected EIPH using echocardiography, we could not distinguish whether the increase in SPAP was related to the pulmonary artery itself or to LV function. Therefore, it is necessary to perform RHC to identify the cause of EIPH in more detail. Finally, although several parameters were identified as predictors of EIPH in patients with CTD, it is unclear whether these parameters were also predictors of future $\mathrm{PH}$ at rest, thereby necessitating prospective longitudinal studies to confirm the findings.

\section{Conclusions}

SPAP at rest and respiratory function, especially VC, could be independent predictors of EIPH in patients with CTD.

\section{Disclosures}

The authors declare no conflicts of interest. M.O. is a member of Circulation Reports' Editorial Team.

\section{References}

1. Galiè N, Manes A, Negro L, Palazzini M, Bacchi-Reggiani ML, Branzi A. A meta-analysis of randomized controlled trials in pulmonary arterial hypertension. Eur Heart J 2009; 30: 394-403.

2. Chung L, Liu J, Parsons L, Hassoun PM, McGoon M, Badesch $\mathrm{DB}$, et al. Characterization of connective tissue disease-associated pulmonary arterial hypertension from REVEAL: Identifying systemic sclerosis as a unique phenotype. Chest 2010; 138: $1383-1394$

3. Thakkar V, Lau EM. Connective tissue disease-related pulmonary arterial hypertension. Best Pract Res Clin Rheumatol 2016; 30: $22-38$.

4. Yasuoka H, Shirai Y, Tamura Y, Takeuchi T, Kuwana M. Predictors of favorable responses to immunosuppressive treatment in pulmonary arterial hypertension associated with connective tissue disease. Circ J 2018; 82: 546-554.

5. Galiè N, Humbert M, Vachiery JL, Gibbs S, Lang I, Torbicki A, et al. $2015 \mathrm{ESC} / \mathrm{ERS}$ Guidelines for the diagnosis and treatment of pulmonary hypertension: The Joint Task Force for the Diagnosis and Treatment of Pulmonary Hypertension of the European Society of Cardiology (ESC) and the European Respiratory Society (ERS): Endorsed by Association for European Pediatric and Congenital Cardiology (AEPC), International Society for Heart and Lung Transplantation (ISHLT). Eur Respir J 2015; 46: 903-975.

6. Nagaoka M, Goda A, Takeuchi K, Kikuchi H, Finger M, Inami T, et al. Nocturnal hypoxemia, but not sleep apnea, is associated with a poor prognosis in patients with pulmonary arterial hypertension. Circ J 2018; 82: 3076-3081.

7. Humbert M, Yaici A, de Groote P, Montani D, Sitbon O, Launay D, et al. Screening for pulmonary arterial hypertension in patients with systemic sclerosis: Clinical characteristics at diagnosis and long-term survival. Arthritis Rheum 2011; 63: $3522-3530$.

8. Doutreleau S, Canuet M, Enache I, Di Marco P, Lonsdorfer E, Oswald-Mammoser $\mathbf{M}$, et al. Right heart hemodynamics in pulmonary hypertension: An echocardiography and catheterization study. Circ J 2016; 80: 2019-2025.

9. Kasai H, Matsumura A, Sugiura T, Shigeta A, Tanabe N, Yamamoto $\mathrm{K}$, et al. Mean pulmonary artery pressure using echocardiography in chronic thromboembolic pulmonary hypertension. Circ J 2016; 80: 1259-1264.

10. Coghlan JG, Denton CP, Grünig E, Bonderman D, Distler O, Khanna D, et al. Evidence-based detection of pulmonary arterial hypertension in systemic sclerosis: The DETECT study. Ann Rheum Dis 2014; 73: 1340-1349.

11. Voilliot D, Magne J, Dulgheru R, Kou S, Henri C, Laaraibi S, et al. Determinants of exercise-induced pulmonary arterial hypertension in systemic sclerosis. Int J Cardiol 2014; 173: $373-$ 379 .

12. Gargani L, Pignone A, Agoston G, Moreo A, Capati E, Badano $\mathrm{LP}$, et al. Clinical and echocardiographic correlations of exerciseinduced pulmonary hypertension in systemic sclerosis: A multicenter study. Am Heart J 2013; 165: 200-207.

13. Kusunose K, Yamada H, Hotchi J, Bando M, Nishio S, Hirata Y, et al. Prediction of future overt pulmonary hypertension by 6-min walk stress echocardiography in patients with connective tissue disease. J Am Coll Cardiol 2015; 66: 376-384.

14. Hochberg MC. Updating the American College of Rheumatology revised criteria for the classification of systemic lupus erythematosus. Arthritis Rheum 1997; 40: 1725.

15. ATS Committee on Proficiency Standards for Clinical Pulmonary Function Laboratories. ATS statement: Guidelines for the six-minute walk test. Am J Respir Crit Care Med 2002; 166: $111-117$.

16. Devereux RB, Alonso DR, Lutas EM, Gottlieb GJ, Campo E, Sachs I, et al. Echocardiographic assessment of left ventricular hypertrophy: Comparison to necropsy findings. Am J Cardiol 1986; 57: 450-458.

17. Rudski LG, Lai WW, Afilalo J, Hua L, Handschumacher MD, Chandrasekaran K, et al. Guidelines for the echocardiographic assessment of the right heart in adults: A report from the American Society of Echocardiography endorsed by the European Association of Echocardiography, a registered branch of the European Society of Cardiology, and the Canadian Society of Echocardiography. J Am Soc Echocardiogr 2010; 23: 685-713.

18. Voilliot D, Magne J, Dulgheru R, Kou S, Henri C, Caballero L, et al. Prediction of new onset of resting pulmonary arterial hypertension in systemic sclerosis. Arch Cardiovasc Dis 2016; 109: $268-277$.

19. Callejas-Rubio JL, Moreno-Escobar E, de la Fuente PM, Pérez LL, Fernández RR, Sánchez-Cano D, et al. Prevalence of exercise pulmonary arterial hypertension in scleroderma. $J$ Rheumatol 2008; 35: $1812-1816$

20. Doran MF, Crowson CS, Pond GR, O'Fallon WM, Gabriel SE. Frequency of infection in patients with rheumatoid arthritis compared with controls: A population-based study. Arthritis 
Rheum 2002; 46: 2287-2293.

21. Geddes DM, Webley M, Emerson PA. Airways obstruction in rheumatoid arthritis. Ann Rheum Dis 1979; 38: 222-225.

22. Vergnenègre A, Pugnere N, Antonini MT, Arnaud M, Melloni $\mathrm{B}$, Treves R, et al. Airway obstruction and rheumatoid arthritis. Eur Respir J 1997; 10: 1072-1078.

23. Loth DW, Lahousse L, Leening MJG, Krijthe BP, Felix JF, Gall $\mathrm{H}$, et al. Pulmonary function and diffusion capacity are associated with pulmonary arterial systolic pressure in the general population: The Rotterdam Study. Respir Med 2017; 132: 50-55.

24. Choudhary G, Jankowich M, Wu WC. Prevalence and clinical characteristics associated with pulmonary hypertension in African-Americans. PLoS One 2013; 8: e84264.

25. Gochuico BR, Avila NA, Chow CK, Novero LJ, Wu HP, Ren P, et al. Progressive preclinical interstitial lung disease in rheumatoid arthritis. Arch Intern Med 2008; 168: 159-166.

26. Steen V, Chou M, Shanmugam V, Mathias M, Kuru T, Morrissey R. Exercise-induced pulmonary arterial hypertension in patients with systemic sclerosis. Chest 2008; 134: 146-151.

27. Nagaya N, Nishikimi T, Uematsu M, Satoh T, Kyotani S, Sakamaki F, et al. Plasma brain natriuretic peptide as a prognostic indicator in patients with primary pulmonary hypertension. Circulation 2000; 102: 865-870.

28. Cavagna L, Caporali R, Klersy C, Ghio S, Albertini R, Scelsi L, et al. Comparison of brain natriuretic peptide (BNP) and NTproBNP in screening for pulmonary arterial hypertension in patients with systemic sclerosis. J Rheumatol 2010; 37: 2064-2070. 